\title{
REFLEXIÓN SOBRE
} LA RAZÓN POÉTICAEN MARÍA ZAMBRANO

Julieta Lizaola*

Si (como dice el griego en el Cratilo)

El nombre es arquetipo de la cosa, en las letras de rosa está la rosa y todo el Nilo en la palabra Nilo.

Jorge Luis Borges.

Las presentes líneas nacen con la necesidad de plantear puntos de reflexión sobre la relación entre poesía y filosofía que contiene la propuesta filosófica de María Zambrano: la razón poética. Los elementos que articulan este planteamiento son: el considerar lo sagrado, como el lugar donde habita lo otro del mundo, lo otro que de él emerge; tanto lo que nuestra conciencia vive como realidad empírica, objetiva, adscrita al tiempo secuencial que nos envuelve, como lo que hemos mantenido oculto y en la sombra. Y, por otro lado, una razón que basa su capacidad de conocimiento en una sensibilidad que advierte la existencia de este otro mundo y que nombramos poesía. Aunados, pensamiento y sensibilidad poética se conforman en un nuevo método filosófico cuya intención es dar cuenta de la parte más íntima del hombre; no es tan sólo vida espiritual deslin-

\footnotetext{
* Departamento Académico de Estudios Generales, ITAM.
}

,


JULIETA LIZAOLA

dada de la interioridad corporal, sino de lo que se siente en el cuerpo y rescata el espíritu bajo la figura de una nueva experiencia; transformando nuestra idea de sensibilidad al hacer una unidad lo que no debió separarse: cuerpo y alma. Es entonces escritura que sale del corazón envolviendo el todo anímico y corporal sin lo cual no podría darse. Los sentimientos se sienten, se reconocen, se manifiestan gracias a la corporeidad que los percibe y los hace suyos. Y es que la poesía ha sido en todo tiempo, vivir, según la carne, adentrándose en ella, sabiendo de su angustia y de su muerte. ${ }^{1}$ Somos esa unidad que el platonismo y el orfismo-pitagorismo desearon deslindar. Lo sagrado y su relación con el conocimiento es cuestión de hondura, de lograr desentrañar las experiencias y aprendizajes que están contenidos dentro, adentro del corazón, es decir de la vida amorosa. Tema agustiniano que Zambrano lleva a la interioridad física; conocer la interioridad es un desentrañarse, es un descifrar lo que guardamos en nuestras entrañas. ${ }^{2}$ La posibilidad de que las palabras den cuenta de la interioridad, que se hagan cargo de lo que se siente y lo que ese sentir significa, es algo que se alcanza con la ayuda iluminadora de la razón que logra insertarlo en un sentido. Es un conocimiento, cuyo objetivo filosófico es dar lugar al surgimiento de una nueva subjetividad, individual y colectiva.

Esto corresponde a la intención de encontrar una forma que advierta tanto el mundo llamado profano como el denominado espacio sagrado, tal como ocurrió en las primeras construcciones literarias. La poesía fue palabra originaria, el decir primero sobre el hecho de estar vivo y descubrirlo; de estar vivo e inscrito en la fugacidad; de estar vivo y encontrarse con la naturaleza y abismado por el universo. Fue ella la que describió los orígenes, las teogonías, las cosmogonías; ${ }^{3}$ la que compuso

${ }^{1}$ María Zambrano, Poesía y filosofía, en Obra Reunida, 1971, Madrid, Aguilar, p. 159.

${ }^{2}$ La psicología y psiquiatría contemporánea, nos hablan de dolores morales que quedan como sensación dolorosa dentro de alguna parte del cuerpo. De ahí la posibilidad de somatizar.

3 “Las cosmogonías son el instrumento poético del orden, la manifestación que anuncia y verifica el paso del caos al orden. Las más venerables 
los primeros cantos a los dioses, las primeras oraciones y plegarias. Ella fue la que dio lugar y definición temporal y espacial. Fue la primera en descubrir el deseo del hombre por ser algo más de lo que es, de poseer un afán de plenitud. Fue ella la que reconoció los diferentes sentires de la vida como algo épico, trágico, lírico... Primero fue el canto, primero fue el ritmo, la música. Antes de otra forma de transmisión fue la oral. Para facilitar el recuerdo de sus contenidos se recurrió a la rima métrica, a la armonía de los versos. Por ello podemos decir que las sociedades que no conocieron la escritura dependieron de la memoria para transmitir sus conocimientos. Pero no sólo se lograba perdurar el recuerdo de algún conocimiento sino también se alcanzaba con ello una forma placentera de obtenerlo; era una vivencia estética lo que se propiciaba recurriendo al ritmo de la poesía.

Con la tensión de la poesía de rescatar el tiempo perdido, su vocación quizá, se enlaza el que la poesía primera que nos es dado conocer sea lenguaje sagrado, verdadero prólogo de lo que llamamos historia. ${ }^{4}$

Los aedos, o cantores épicos, eran poetas de profesión que componían y recitaban tomando como base un patrimonio de material tradicional. Por todo lo anterior, podemos afirmar que la poesía es canto y es anterior a la filosofía; también podemos deducir que la aparición de la escritura está tan relacionada con el surgimiento de la razón como lo está la memoria con la poesía: formas técnicas que derivan a su vez, en diferentes formas de lenguaje $y$, por lo mismo, de conocimiento a transmitir.

[...] el ritmo es uno de los más profundos si no el más decisivo de todos los fenómenos que constituyen la vida y muy espe-

comienzan: 'En el principio era el caos’. 'En el principio era la noche’ dice la órfica, donde el amor encuentra su anuncio misterioso.” Citado en: Zambrano, El hombre y lo divino, 1992, Madrid, Siruela, p. 246.

${ }^{4}$ María Zambrano, Poesía y filosofía, op. cit., p. 222. 
JULIETA LIZAOLA

cialmente en la extraña vida que se deposita en las obras de humana creación. En la aurora de la humana historia fue el ritmo el descubrimiento inicial en cuanto al conocimiento íntimo de las cosas. ${ }^{5}$

El lenguaje sagrado realiza una acción de fundamental importancia: la de abrir espacios vitales; por ello, para Zambrano los rituales piden y realizan la continuación de lo que es la palabra sagrada: acción. Palabra definida por Platón como el diálogo silencioso del alma consigo misma. Palabras y rituales unifican, religan, vivifican, permiten acceso a otras dimensiones del espacio-tiempo.

La principal herejía de Zambrano ha sido recuperar las categorías religiosas como lo que originalmente fueron: lenguaje poético que daba cuenta de un orden del mundo; liturgias, fórmulas sacras, son la patria de donde procede la poesía. Recuperar ese sentido ha sido una propuesta atrevida, heterodoxa, que obliga a mirar la construcción de la cultura desde su nudo originario: la inexistente separación entre poesía, religión y filosofía; es decir, desde la necesidad primordial de construir socialmente una realidad profana donde poder vivir. Observar desde la fundamentación de estas tres miradas, cuando aún eran una, no sólo permite observar su raíz común, sino también, el agua de la que bebe esta raíz: la desvalidez humana y su contraparte, el amor por la vida. Desvalidez y amor, plenitud y carencia son lo que ha permitido cimentar una posibilidad de vida humana. Zambrano se preguntó incesantemente por quién da cuenta de ello; la respuesta corresponde al lenguaje de lo sagrado: a la poesía.

\section{II}

¿Qué es lo que eleva el oscuro ímpetu de la vida al alma, y el alma a la razón sustentando la separación entre filosofía y poesía ? ${ }^{6}$ Según la

${ }^{5}$ María Zambrano, Poema y sistema, O. R., op. cit., p. 240.

${ }^{6}$ Ibid., p. 159. 
autora, es el amor. Éste nos descubre el ser y el no ser, lo que somos y lo que no somos, nos señala la ausencia, la oquedad, el infierno. El amor hecho palabra encontró que su forma arropaba una ruptura: una palabra filosófica y una palabra poética. Dos voces para dar cuenta del mundo desde diferentes dimensiones. La separación poesía-filosofía es un logos que se divide, para ser fiel, según Zambrano, a las formas en que el amor a su vez ha sido escindido. En algún momento del desarrollo del lenguaje nacieron los dos géneros literarios. Y más que separación fue desgarradura, pues desde la perspectiva de la autora, esto no fue una evolución de las formas de habla, sino la manifestación de un desgajamiento interior. Si el amor se ha fracturado, esta condición marca diferentes formas de vivirlo, siempre incompletas, siempre en falta, carentes, tal y como el hombre se encuentra, ¿Cuál de las dos es la elegida para construir el mundo? Las dos, responde Zambrano, la palabra amorosa no puede seguir construyendo sólo desde el anhelo nostálgico de la plenitud o desde la mortificación de la carencia.

Desde Pitágoras y más claramente en Platón, sabemos que lo que nos lleva al conocimiento es el amor. La filosofía ha sido palabra que ha respondido al anhelo del amor a la sabiduría, ha respondido a una cuestión emocional, afectiva, con la vida, la que nos empuja a ir más allá de nuestras limitaciones cognitivas. Se dijo entonces que era una forma de llegar al verdadero conocimiento, a mirar la pureza y el encuentro máximo, el encuentro con el Sumo bien, con la Verdad, con Dios. ¿Cómo se liga esta idea del amor con la verdad y con la divinidad? Es un tema que tiene un hilo conductor: la amplitud y la idea de perfectibilidad de la vida espiritual. La potencialidad y perfección última recorren este sendero. El problema que aquí aparece es que éste fue perdiendo la sangre, la carne, el cuerpo. Podemos señalar que lo que Zambrano desea es dejar a un lado la negación de este mundo concebido como un paso terrenal que nos libera de la cárcel del cuerpo y sus sentidos y sentimientos. Platonismo y Cristianismo, uno haciendo del acceso a la verdad un proceso descarnado y otro haciendo de la encarnación divina su voluntad, ambos niegan la inseparable unidad: el amor y el conocimiento son de este mundo; sentimientos y razones 
JULIETA LIZAOLA

son de este mundo y la razón poética desea hacerse cargo de ambos para unificar el contenido del alma humana.

Si Platón quiere salvar las apariencias, no puede renunciar a salvar el amor que nace de la carne, pero tiene que separarlo de ella; toda la teoría platónica del amor es un desasimiento del cuerpo, su incorporación al mundo de la dialéctica [...]. ${ }^{7}$

El amor en el pensamiento de Zambrano, en consonancia con su autodenominada filiación órfico-pitagórica, pasa como el elemento que nos lleva hacia lo otro, a conocer lo otro. Si recordamos el nacimiento de Eros según Hesíodo lo encontramos como uno de los Dioses primigenios: Antes que todas las cosas fue Caos; y después Gea la de amplio seno [...] y después Eros, el más hermoso entre los Dioses Inmortales, que rompe todas las fuerzas, y que de todos los Dioses y de todos los hombres domeña la inteligencia y la sabiduría en sus pechos. ${ }^{8}$ Con Eros nacerá la posibilidad de la unidad y el conocimiento. La filosofía presocrática le dará lugar de fundamento el cual será recuperado más tarde por Platón. El amor es el que mueve el universo, el día, la noche. La perfección del universo es un mensaje amoroso, toda materia y su energía es percibida como un acto de amor para el alma.

[...] los órficos dicen que la Noche de las alas negras, Diosa por la que incluso Zeus sentía temor reverente, fue cortejada por el Viento y puso un huevo de plata en el seno de la Oscuridad; y es que Eros, a quien algunos llaman Fanes, salió de ese huevo y puso el Universo en movimiento. ${ }^{9}$

Empédocles sustenta que el amor logra unir los diferentes elementos para originar las cosas singulares, para que sean, mientras el odio

${ }^{7}$ María Zambrano, Poesía y filosofía, 1987, México, FCE, p. 64.

${ }^{8}$ Hesíodo, Teogonía, 1981, México, Porrúa, p. 4-5.

${ }^{9}$ Robert Graves, Los mitos griegos, 1994, Madrid, Alianza, p. 33 (negritas nuestras). 
las impide. El movimiento para el hombre griego era un impulso generado por Eros. En este sentido, Zambrano considera de radical importancia que Platón haya salvado al amor, lo haya tomado entre las cosas verdaderas que nos alejan de las apariencias, permitiendo el conocimiento de la Verdad y la Belleza, del Sumo Bien. Por lo que podemos deducir que el amor platónico perfecto es el que manifiesta el deseo del bien. El amor situado entre penia y poros, entre poseer y no poseer, en su aspiración hacia lo amado engendra en la belleza.

Aristóteles recuperará la idea del amor también como movimiento, pues sólo lo que es perfecto no requiere nada y por lo tanto se mantiene impasible en su lugar. La vida del hombre es imperfecta, es movimiento continuo porque es necesidad permanente. Es gracias a que Dios permite el amor que esto puede realizarse. En ambos casos, Platón y Aristóteles, el amor es vehículo de la virtud y de la posibilidad de una vida eterna. El amor griego hemos dicho es movimiento y como tal nos acerca a lo otro que encierra en sí nuestra necesidad.

En su profunda infinitud vi internarse, unidas por el amor en un volumen, las hojas desperdigadas de todo el universo [...] La forma universal de esta compleja trama creo haber visto, porque al decir esto, siento en mí crecer el gozo. ${ }^{10}$

Por lo anterior, podemos considerar que el amor en Occidente ha nacido con un sentido ontológico: el amor mueve al amante hacia lo amado, lo mueve a lo más perfecto, hacia el ser que cada cosa es en su perfección. La diferencia entre el amor griego y cristiano, en términos generales, es que el Sumo Bien en su perfección no necesita nada, por lo cual no necesita amar, sólo lo posibilita; en el cristianismo Dios es identificado con el amor en virtud de su exuberancia.

La idea del amor, esencialmente relacionada con el conocimiento -Eros el impulsor del movimiento y de la vida- es aceptado por Zambrano en el mismo sentido, es decir, como origen de conocimientos y

${ }^{10}$ Dante, La divina comedia. 
JULIETA LIZAOLA

arte, de todo despertar y crear. La autora reconocerá que Platón, en su ascetismo filosófico, logra salvar el amor que da lugar a la poesía y a la filosofía: llega a afirmar que si no fuera por Platón el amor sería uno de los elementos segregados de lo vital para el hombre. Salvado el amor es posible su integración en la caridad cristiana, y lo más importante, en el reconocimiento del amor personal. Así, éste es lo que sostiene la movilidad y construcción humana, es decir a la persona, y por lo mismo, lo que en su teoría filosófica tiene el papel de cimiento, de piedra angular: plantear que la escisión del amor ha dado lugar a diferentes formas de conocimiento. Y llevados por el amor los hombres recorrerán ese largo camino cuyo logro es la propia unidad, el llegar a ser de verdad uno mismo. El amor engendra siempre. ${ }^{11}$

\section{III}

Un nuevo acceso a la realidad es lo que late en la formulación teórica de la razón poética. Zambrano encontrará en la razón y en la poesía los elementos que amplían nuestras capacidades y ennoblecen nuestra condición de hombres estructurados por la necesidad. Es el logos, el logos no dividido a lo que ella aspira: a una palabra que no necesite definirse como poética o como filosófica. ¿Es posible esto? ¿Es posible nombrar el universo sin necesidad de hacer una especificación de tal naturaleza? Si esto es posible lo será por que habremos llegado a la posibilidad de hacer realidad un sueño. Un sueño no sólo soñado por Zambrano sino compartido por muchos poetas y filósofos -como los románticos, los poetas místicos, Machado, Bergson, por ejemplo. Es el sueño de la unidad, de la armonía del cosmos, reflejada en el corazón del hombre y las palabras que de él nacen. Mas la pregunta que sigue abierta es si es posible resolver la necesidad de conocimiento que señaló Aristóteles como propia de todo hombre y hacerlo sin pasar por el desgajamiento del logos en poesía y filosofía.

${ }^{11}$ María Zambrano, El hombre y lo divino, op. cit., p. 254. 
¿Es posible esta unidad? Lo intentaremos desarrollar desde la condición de la poesía señalada por Zambrano como parte fundamental de cualquier conocimiento que se plantee reflexionar sobre el hombre. La poesía, entonces, deriva en dos aspectos fundamentales: hacer transparente, cristalino, lo que ella ve y poder hacerlo sin necesidad de justificación conceptual; en ello radica su carácter de palabra autónoma.

Visto desde cierta distancia, esto no tendría por qué implicar un problema; podría considerarse la separación entre filosofía y poesía como el resultado de dos formas de dar cuenta de la vida humana y su diversidad, lo cual podría ser tomado como manifestación de la riqueza cultural que se ha logrado desarrollar. Sin embargo, para Zambrano, esto no es así. La escisión que sufre el amor y se manifiesta en el desarrollo del alma occidental tiene otra cara, y esto es lo que preocupa y problematiza la autora, el ser raíz de la escisión cultural. Fenómeno que se muestra en la separación, la desgarradura, la fragmentación del conocimiento. Zambrano considera que no fue fácil, ni simple, el llegar a algo que Aristóteles definió como el natural deseo de conocimiento que cada hombre posee. ${ }^{12}$ ¿Cómo, se pregunta, ocurrió esto? ¿De qué forma llegó a la conciencia del hombre la imperiosa necesidad de conocer lo que le provoca asombro, admiración? Fue un proceso largo, sinuoso, lo que logró que el conocimiento apareciera como una forma de pensamiento racional y sistémica. Y es eso lo que nuestra autora quiere que no se olvide, que se recuerde, que permanezca como memoria viva: que la razón sistémica llegó al mundo bajo una intencionalidad pragmática: construir una ciudad, con leyes y justicia. Una ciudad con la arquitectura de la justicia como principio y posibilidad de libertad y felicidad.

El problema central y su paradoja radica en que la razón como racionalismo no es justa, no puede dar lugar a arquitecturas sociales que no sean desiguales, que no sean relegadoras. Tenemos el ejemplo

12 “Todos los hombres tienen naturalmente el deseo de saber. El placer que nos causan las percepciones de nuestros sentidos son una prueba de esta verdad”: Aristóteles, Metafísica, Libro I. 
JULIETA LIZAOLA

en La República platónica. La razón olvida que todos y todo son parte de una unidad; la razón considera su pleno derecho y conquista el decir -qué sí, y qué no es racional y por lo tanto real-qué es verdadero y qué es apariencia, qué puede ser alimento o algo que debilite el sentir del alma. Sin embargo su primicia nace de la misma injusticia que dice querer eliminar. El origen de su injusticia -y por tanto de su violencia- radica en tener como principio el determinar qué cosas son más reales, más verdaderas, que puestas en un determinado orden implican un valor asignado que va mostrando una figura verdadera. Si esto no implicara la negación de otras formas de orden del pensamiento, de otras formas de verdad, no habría necesidad de justificar dominio alguno sobre la verdad y su adquisición. La violencia con que la filosofía arranca conocimientos a los fenómenos será flor renacentista y moderna: lo que importa es llegar a las cosas sin importar el método. Lo que más tarde entenderemos con Maquiavelo como lo que importa es el fin y no los medios: $:^{13}$ El fin es el poder. Sin embargo, no es una reprobación moral lo que aquí preocupa sino lo que hay en el núcleo de la violencia filosófica; raíz de un racionalismo que va derivando en absolutismo, plenamente confiado de su hacer, de su buen camino, justificando hasta las últimas consecuencias de su actuar, ya sean éstas ontológicas, éticas, sociales, políticas, estéticas, morales... Es la adquisición de una verdad última, justificadora, legitimadora y finalmente legisladora. El racionalismo es entonces un camino a desandar: su arrogancia sobre el conocimiento se ha convertido en obstáculo tanto para el conocimiento como para su objetivo final: formular diversas formas que permitan hacer surgir nuevas miradas, transformarse en cauce de vida, en camino-guía para la salvación y liberación humana. El problema entonces radica en sus cimientos y este punto será para Zambrano el elemento nuclear de nuestra cultura, no sólo fragmentada, sino también negadora, absolutista, prepotente y capaz de prescindir

13 “Trate, pues, un príncipe de vencer y conservar el Estado, que los medios siempre serán honorables y loados por todos”: Maquiavelo, El Príncipe, cap. XVIII. 
de realidades y vidas que no van de acuerdo con sus postulados. Esto es lo que es necesario analizar.

Trataremos, no de explicar cómo se desarrolla este fenómeno, sino descifrar cómo surge esta separación desde la perspectiva de la filósofa española. Lo que se problematiza aquí es la relación entre las palabras y las cosas. ¿Cuál de las dos palabras, poética o filosófica, sostiene esta relación fundamental para el conocimiento? Cuál nombra más certeramente parece ser el debate entre los beligerantes de la poesía como acceso al conocimiento y los detractores del racionalismo por haber empobrecido la vida amorosa y, y por lo tanto, cognoscitiva del hombre.

La división entre poesía y filosofía también se ha entendido como la división entre arte y pensamiento. Si bien poesía y filosofía corresponden a la necesidad de poner las cosas más allá, de hacerlas ir más allá de ellas mismas, las formas varían: una corresponde a la dimensión de la metáfora y otra a la dimensión metafísica. Zambrano considera que la metáfora poética es una necesidad ineludible para el conocimiento, ya que hay verdades que sólo se nos pueden dar metafóricamente; verdades inefables para el pensamiento teórico pero accesibles para la sensibilidad poética. De esta unión, considera la autora, surge un conocimiento que no se traduce necesariamente en violencia; un conocimiento que no derive en dominación, haciéndose la fantasía de estar constriñendo lo inagotable.

La poesía como conocimiento sin necesidad de sujetarse a normas epistemológicas no posee el sentido de la justicia. La justicia en todo caso sería hacer palabra de todo lo existente, dar cuenta de las vicisitudes del vivir, de lo que implica para el hombre estar en el mundo sin más obligación que la de vivir la plenitud de la realidad, aunque sea contradictoria e irracional, aunque no tenga un propósito eficiente ni eficaz; su tarea, si es que tiene alguna, es recrear la vida, no dejar que los momentos transcurran devorados, negados, olvidados, lo suyo es la memoria de lo vivido, de lo más sensiblemente vivido. 
JULIETA LIZAOLA

La poesía es la conciencia más fiel de las contradicciones humanas, porque es el martirio de la lucidez, del que acepta la realidad tal y como se da en el primer encuentro. Y la acepta sin ignorancia, con el conocimiento de su trágica dualidad y de su aniquilamiento final. ${ }^{14}$

La poesía no requiere decir por qué existe, ni qué es lo que pretende. Su palabra es fiel a las contingencias humanas. Y este carácter de independencia es lo que Zambrano quiere recuperar para la acción del pensar: no olvidar, no desdeñar las experiencias vividas por no corresponder éstas a ninguna teoría del conocimiento. Desea esta libertad del habla que puede recuperar lo experimentado reflexionándolo, llevándolo a la razón, e iluminar las tinieblas con que vivimos nuestra estancia en la Tierra. Esta libertad y autonomía de la palabra aunada al hecho de reflexionar sobre ella es lo que permite abrir nuevos sentidos. De ahí que, desde la perspectiva de Zambrano, sea inevitable que el pensar se alimente de otras formas de conocimientos y saberes. La necesaria unión poesía-filosofía contiene un argumento por mor de la verdad: las diferencias entre una verdad poética y una verdad filosófica no son antagonismos, son la armonía de los contrarios, el arco y la lira, la tensión que sustenta al cosmos. Zambrano desea reencontrar al hombre como una totalidad, si bien totalidad siempre inacabada, capaz de ser comprendida como Una.

El amor dividido busca lo que acuciantemente requiere encontrar: la palabra que asiste y sostiene el ser. La separación entre filosofía y poesía es un desgarramiento del alma entre dos necesidades: contemplar el mundo y transformarlo.¿Cuál de las dos necesidades, en el caso de ser dos, es la nacida en zonas más hondas de la vida humana? ¿Cuál, la más imprescindible: la carencia o la plenitud? Zambrano sufre en su propia carne la desgarradura entre poesía y filosofía. Filósofa y poeta, enamorada del carácter contingente del mundo, de las apariencias furtivas del acontecer mundano y enamorada de la razón como

${ }^{14}$ María Zambrano, Poesía y Filosofía, O. R., op. cit., p. 164. 
MARÍA ZAMBRANO

sendero de libertad. No hay en su teoría ningún interés por poseer única verdad; lo suyo es aceptar, acatar, abrirse a la vida primero imagen y luego palabra; seguir caminos que se curvan, senderos que se bifurcan, claros que se abren, ríos subterráneos que contienen dentro de sus aguas oscuras consuelo y esperanza.

La razón poética de Zambrano quiere dar cuenta de los misterios del alma contemporánea, de las grandes aporías, de las vicisitudes del laberinto que es la vida íntima, con la intención de mostrarnos espacios vitales no vistos aún por la razón. La elaboración teórica de Zambrano nos invita a mirar más y más adentro, en el miedo y el dolor de encontrarnos con nuestras sombras, temor y temblor nos muestran otra cara no menos real y necesitada de razón y sentido: conciencia de la desdicha del alma moderna, conciencia de la enormidad del mundo que hemos anulado, La provincia del hombre ${ }^{15}$ que hemos excluido del pensamiento.

La relación poesía-filosofía en la obra de Zambrano, es entonces, un conflicto que se origina en el carácter mismo del amor, en nuestro ir y venir entre la carencia y la plenitud, por lo mismo no es sólo un problema de conocimiento o un problema de diferentes lenguajes literarios. El rompimiento de la palabra en palabra poética y palabra filosófica se ha traducido, por un lado, en la necesidad de la palabra como recreación de la realidad, aún la más mínima; y, por otro, la necesidad de la palabra metódica, sistemática, en posesión de conocimientos sólidos y fiables, que puedan dirigirse a conducir la transformación del mundo. Esto no puede ser entendido ni aceptado como un proceso natural, como querría verse desde una óptica evolucionista o positivista. Si nos detenemos, podemos mirar que su dimensión corresponde a un desgarramiento cultural: el alma se ha desgajado en su necesidad de contemplación y transformación, dividida en dos miradas irrenunciables. Miradas al parecer antagónicas, irreconciliables según argumentos dados en la historia del pensamiento occidental. Pareciera, dice la autora, que es irremediable que el hombre se nos ofrezca en

15 Título de un libro de notas de Elías Canetti. 
JULIETA LIZAOLA

dos mitades, sin poder dar cuenta de su vida del alma. ${ }^{16} \mathrm{Y}$ sin embargo, para Zambrano son complementarias, pues la una con la otra pueden ofrecer un horizonte más amplio, una razón poética donde el hombre pueda descifrar sus afanes por encontrar la aurora.

${ }^{16}$ Poesía y filosofía, O. R., op. cit., p. 116. 